ORIGINAL ARTICLE

\title{
Sexual behaviour of young people in international tourist resorts
}

\author{
M A Bellis, K Hughes, R Thomson, A Bennett
}

Sex Transm Infect 2004;80:43-47. doi: 10.1136/sti.2003.005199

See end of article for authors' affiliations

....................

Correspondence to: Professor Mark A Bellis, Centre for Public Health, Liverpool John Moores University, 8 Marybone, Liverpool L3 2AP, UK; m.a.bellis@livjm.ac.uk

\begin{abstract}
Background/objectives: Increasingly, young people travel abroad to experience nightlife in international resorts. Although media coverage of such resorts suggests high levels of sexual activity, little empirical data are currently available. We have measured: 3 year trends in sexual behaviour of young people visiting Ibiza, levels of sexual risk taking, and their relation to substance use. Additionally, in 2002 we identified levels of homosexual sex and sexual interactions between UK residents and individuals from other countries.

Methods: Data were collected from visitors to lbiza between 2000 and 2002 just before they left the island. Information on sexual health was surveyed using a short anonymous questionnaire.

Results: Over half of individuals (56.0\%) visiting Ibiza had sex with at least one person, with $26.2 \%$ of males and $14.5 \%$ of females having sex with more than one individual. However, of those arriving without sexual partners (75.5\%) just under half (47.5\%) have sex in Ibiza and most of these (62.4\%) always used condoms. Having any sex abroad was associated with using illicit drugs and having more sexual partners in the 6 months before visiting lbiza. However, having unprotected sex or sex with more than one person was associated with smoking as well as having higher numbers of sexual partners before their visit. Overall, $8.6 \%$ of individuals had sex with a non-UK resident in Ibiza although such individuals were no more likely to have sex without condoms.

Conclusions: Substantial numbers of individuals visiting international nightlife resorts have unprotected sex with people they meet while abroad. This poses an increasing threat to the sexual health of UK residents but as yet little attention has been paid to developing interventions that might reduce sexual risk taking among young people holidaying abroad.
\end{abstract}

$\mathrm{R}$ ecent years have seen dramatic rises in sexually transmitted infections (STIs) across the United Kingdom ${ }^{1}$ accompanied by levels of teenage pregnancy substantially higher than those in most Western European countries. ${ }^{2}$ However, the behaviours that contribute to poor sexual health are not constant throughout the year but peak around Christmas and again during the summer months. Thus, in winter individuals enjoy the freedom of Christmas holidays, often consume alcohol to excess and, in some cases, subsequently engage in unprotected sex. ${ }^{3}$ Equally, summer holidays provide a similar escape from the social mores of family, work, or education again accompanied by increases in sexual risk. ${ }^{45}$ As a result, both periods are followed by rises in demand for emergency contraception, increased attendance at sexual health clinics, and additional requests for terminations among young people. ${ }^{6}$ Such cycles of sexual behaviour are well established. More recently however the proliferation of cheap air travel and international nightlife resorts has resulted in greater opportunities (especially in summer) for young people to socialise abroad in a distant, often carefree, environment. The potential for such international settings to contribute to rises in STIs and unwanted pregnancies is substantial with individuals drinking more, ${ }^{7}$ taking more drugs $^{4}$ and socialising more frequently ${ }^{8}$ than when at home. Equally, mixing between individuals from different countries provides an opportunity for the international transmission of STIs ${ }^{9}$ especially where access to protective measures (for example, condoms) is absent, confusing, or poorly promoted..$^{10}$

Epidemiological studies of UK residents who acquire STIs often identify sexual contact abroad as a risk factor for infection (for example, syphilis, ${ }^{11}{ }^{12} \mathrm{HIV}^{13}{ }^{14}$ ) and the risk posed by international transmission of communicable disease has now been recognised in UK health policy. ${ }^{15}$ Elsewhere, and in the United Kingdom, limited data on the holiday behaviour of young people travelling within their country of residence suggest changes in sexual behaviour associated with vacations away from home. ${ }^{5816}$ Each year, over 250000 young people from the United Kingdom alone visit the top international dance resort of Ibiza (Spain) ${ }^{17}$ with many more visiting resorts in Greece, Cyprus, and elsewhere. ${ }^{18}$ Despite such numbers travelling abroad and the increasing prevalence of many STIs, ${ }^{1}$ few empirical data are available on the epidemiology of sexual behaviour in such international resorts.

In order to quantify the risks to sexual health posed by travel to international dance resorts, here we examine the sexual behaviour of UK residents holidaying in the leading nightlife resort of Ibiza. Furthermore, using data on frequency of unsafe sex and its relations with substance use, we examine opportunities to protect the sexual health of young people abroad.

\section{METHODS}

Three cross sectional surveys were undertaken at Ibiza airport in the summers of 2000, 2001, and 2002. Individuals were approached at the airport while waiting to check in for their flights back to the United Kingdom and asked to complete a short, anonymous questionnaire. Questionnaire length was limited by relatively short periods of time being available to each respondent. However, data collected included individuals' basic demographics, main reasons for visiting the island and levels of illicit substance, alcohol, and tobacco use in Ibiza and in the United Kingdom. ${ }^{19}$ Details collected relating to sexual health included the number of sexual partners people had in Ibiza, the number over the 6 months 
before visiting the island, whether individuals visited the island with a sexual partner, and whether people had received sexual health promotion literature while in Ibiza. Levels of condom use in Ibiza were also measured but, owing to limitations in questionnaire length, use of other contraceptive methods was not, with priority being given to issues relating to STI prevention. In 2002 however, determining levels of homosexual sex and levels of sex with non-UK residents were considered sufficiently important to include additional questions covering these issues. Critically, extending the questionnaire did not reduce compliance.

The questionnaire was administered by trained researchers who approached all individuals and asked if they had time to fill in a short, anonymous questionnaire (2000, $\mathrm{n}=752$; $2001, \mathrm{n}=374 ; 2002, \mathrm{n}=1241$ ). Those who indicated they had time were only then informed of the nature of the questionnaire (2000, $\mathrm{n}=526 ; 2001, \mathrm{n}=270 ; 2002, \mathrm{n}=937$ ) and among these compliance was $88.0 \%(2000, \mathrm{n}=463)$, $89.3 \% \quad(2001, \mathrm{n}=241)$, and $92.6 \% \quad(2002, \mathrm{n}=868)$. All individuals completed the questionnaire unsupervised and returned it in a sealed envelope.

Analyses of data for all years are limited to those aged 1635 and those visiting the island for a period of 90 days or less (2000, $\mathrm{n}=463 ; 2001, \mathrm{n}=241 ; 2002, \mathrm{n}=855$ ). Within these samples, mean lengths of stay were 11.62 days (2000), 9.78 days (2001), and 10.05 days (2002). All analyses were undertaken using SPSS and utilised $\chi^{2}$, Wilcoxon sign rank tests, and logistic regression methodologies. ${ }^{20}$ For the purposes of this paper the term illicit drugs refers to the drugs amphetamine, ketamine, cannabis, ecstasy, LSD (Dlysergic acid diethylamide), cocaine and GHB (gammahydroxybutyrate). Having had unsafe sex in Ibiza is defined as not always using a condom when having sex with any person on the island.

\section{RESULTS}

Initial analyses deal with all individuals sampled (2000-2) and differences between years are explored later as part of logistic regression analyses. Table 1 identifies the basic demographic features of all individuals sampled over the 3 year period, consumption of substances, and reasons for visiting Ibiza. Table 2 presents bivariate analyses of sexual behaviour in Ibiza. Both tables are stratified by sex and whether individuals visited Ibiza with an existing sexual partner. For all individuals visiting Ibiza, only 14.7\% appear to be holidaying on the island explicitly to look for sex, although among males this figure rises to $22.4 \%$ (table 1 ). However, the number of individuals actually having sex during a single visit is much higher with most individuals $(56.0 \%)$ visiting the island having sex at least once and $26.2 \%$ of males and $14.5 \%$ of females having sex with more than one person (table 2).

Table 3 presents the results from logistic regression analyses undertaken to identify factors independently related to whether people had sex in Ibiza and, of those having sex, who had unprotected sex at least once and who had sex with more than one person. Having sex, having unprotected sex, and having sex with more than one person abroad were all positively related to the number of sexual partners individuals had during their 6 months before visiting Ibiza. Those in younger age groups (16-25 years) were also more likely to have sex in Ibiza (table 3).

Individuals' sexual behaviour in Ibiza was strongly related to whether they were holidaying with a sexual partner (that is, $19.6 \%$ of males and $31.0 \%$ of females; overall $24.5 \%$ ). Those with partners were significantly more likely to have sex in Ibiza but less likely to always use condoms (table 3). For individuals who had sex in Ibiza but who arrived without a sexual partner (see table 2 ), their median number of sexual

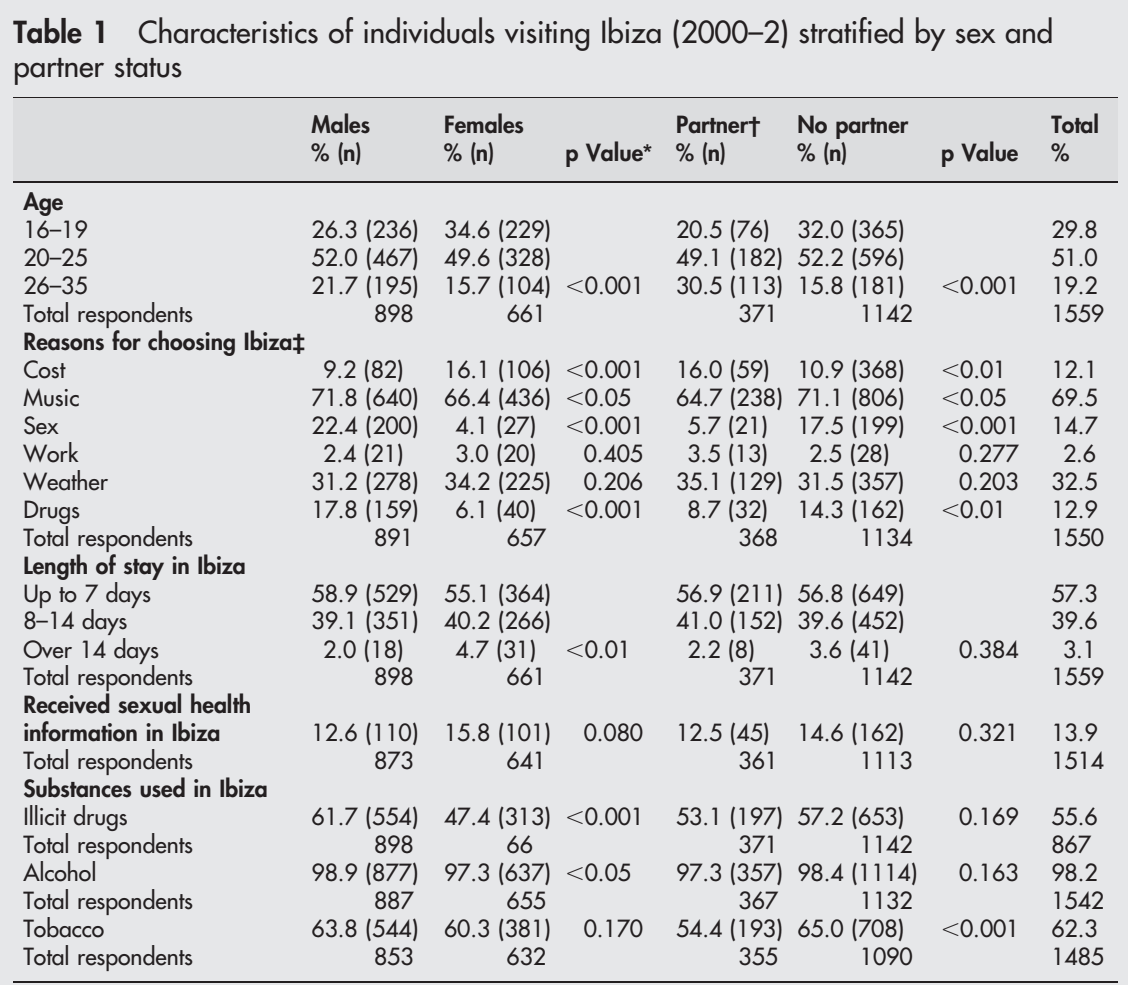

*Statistics utilise $\chi^{2}$ analyses.

tPartner indicates individuals arriving in Ibiza already with a sexual partner.

flndividuals were permitted to pick more than one reason for visiting lbiza. 


\begin{tabular}{|c|c|c|c|c|c|c|c|}
\hline & Males (\%) & $\begin{array}{l}\text { Females } \\
(\%)\end{array}$ & p Values* & $\begin{array}{l}\text { Partnert } \\
\text { (\%) }\end{array}$ & $\begin{array}{l}\text { No partner } \\
(\%)\end{array}$ & $\mathrm{p}$ Value & Total (\%) \\
\hline \multicolumn{8}{|c|}{ Number of sexual partners in Ibiza } \\
\hline None & $42.7(326)$ & $45.8(260)$ & & $18.2(59)$ & $52.5(515)$ & & 44.0 \\
\hline 1 & $31.2(238)$ & $39.8(226)$ & & $75.6(245)$ & $21.4(210)$ & & 34.8 \\
\hline $2-5$ & $15.2(116)$ & $11.3(64)$ & & $2.8(9)$ & $17.1(168)$ & & 13.5 \\
\hline 6 or more & $11.0(84)$ & $3.2(18)$ & $<0.001$ & 3.4 (11) & $9.0(88)$ & $<0.001$ & 7.7 \\
\hline Total respondents & 764 & 568 & & 324 & 981 & & 1332 \\
\hline \multicolumn{8}{|c|}{ Of those having sex, number of unprotected sexual partners in Ibiza } \\
\hline None & $55.4(226)$ & $56.9(148)$ & & $41.4(84)$ & $62.4(281)$ & & 56.0 \\
\hline 1 & $26.0(106)$ & 35.4 (92) & & 53.7 (109) & $18.9(85)$ & & 29.6 \\
\hline $2-5$ & $12.3(50)$ & $7.3(19)$ & & $3.0(6)$ & $13.8(62)$ & & 10.3 \\
\hline 6 or more & $6.4(26)$ & $0.4(1)$ & $<0.001$ & $2.0(4)$ & $4.9(22)$ & $<0.001$ & 4.0 \\
\hline Total respondents & 408 & 260 & & 203 & 450 & & 668 \\
\hline \multicolumn{8}{|c|}{ Number of sexual partners in 6 months before visiting Ibiza } \\
\hline None & $11.8(93)$ & $11.6(68)$ & & $4.3(14)$ & $14.2(145)$ & & 11.7 \\
\hline 1 & $43.4(341)$ & $59.1(346)$ & & $86.2(282)$ & 38.6 (394) & & 50.1 \\
\hline $2-5$ & $34.6(272)$ & $26.2(153)$ & & $7.3(24)$ & 38.1 (389) & & 31.0 \\
\hline 6 or more & $10.3(81)$ & $3.1(18)$ & $<0.001$ & 2.1 (7) & $9.0(92)$ & $<0.001$ & 7.2 \\
\hline Total respondents & 787 & 585 & & 327 & 1020 & & 1372 \\
\hline
\end{tabular}

partners in Ibiza was two. This did not differ significantly from the total number of partners they accumulated during the 6 month period before they visited Ibiza (median $=2$; $\mathrm{Z}=1.67, \mathrm{p}=0.09$ ). Around a fifth of this group had unprotected sex in Ibiza with at least two individuals (table 2).
Among all individuals having sex in Ibiza, the proportion having unprotected sex increased after 2000 while the proportion having more than one partner decreased (table 3).

For 2002 only, data were available to analyse sexual behaviour independently for heterosexual and same sex acts

\begin{tabular}{|c|c|c|c|c|c|c|}
\hline & \multicolumn{2}{|c|}{ Had sex } & \multicolumn{2}{|c|}{ Had unprotected sex ${ }^{*}$} & \multicolumn{2}{|c|}{ Had $>1$ sexual partner } \\
\hline & AOR & $(95 \% \mathrm{Cl})$ & AOR & $(95 \% \mathrm{Cl})$ & AOR & $(95 \% \mathrm{Cl})$ \\
\hline $\begin{array}{l}\text { Age } \\
\text { (ref) 26-35 }\end{array}$ & 1 & & 1 & & 1 & \\
\hline $20-25$ & 2.12 & $(1.42$ to 3.16$)$ & NS & - & NS & - \\
\hline $16-19$ & 1.51 & (1.07 to 2.14$)$ & NS & - & NS & - \\
\hline \multicolumn{7}{|l|}{ Sex } \\
\hline Male & NS & - & NS & - & 1.79 & $(1.18$ to 2.70$)$ \\
\hline \multicolumn{7}{|l|}{ Substance use in Ibiza } \\
\hline No alcohol & 1 & & 1 & & 1 & \\
\hline Used alcohol & NS & - & NS & - & NS & - \\
\hline No tobacco & 1 & & 1 & & 1 & \\
\hline Used tobacco & NS & - & 1.48 & (1.06 to 2.14$)$ & 1.89 & $(1.18$ to 2.70$)$ \\
\hline No illicit drugs & 1 & & 1 & & 1 & \\
\hline Used illicit drugs & 1.37 & (1.05 to 1.79$)$ & NS & - & NS & - \\
\hline \multicolumn{7}{|l|}{ Length of stay } \\
\hline $8-14$ days & NS & - & NS & - & 1.67 & $(1.11$ to 2.50$)$ \\
\hline over 14 days & NS & - & NS & - & 2.80 & (1.02 to 7.28$)$ \\
\hline $\begin{array}{l}\text { Year } \\
\text { (ref) } 2000\end{array}$ & \multicolumn{2}{|c|}{ Year } & 1 & & 1 & \\
\hline 2001 & NS & - & 2.18 & (1.30 to 3.65$)$ & 0.64 & $(0.39$ to 1.15$)$ \\
\hline 2002 & NS & - & 1.18 & $(0.81$ to 1.71$)$ & 0.53 & $(0.34$ to 0.81$)$ \\
\hline \multicolumn{7}{|c|}{ Received sexual health information } \\
\hline (ref) No & 1 & & 1 & & 1 & \\
\hline \multirow{2}{*}{\multicolumn{7}{|c|}{ Holiday with partner }} \\
\hline & & & & & & \\
\hline Yes & 7.54 & (5.21 to 10.89 ) & 3.04 & (1.96 to 4.73$)$ & 0.08 & $(0.05$ to 0.13$)$ \\
\hline \multirow{2}{*}{\multicolumn{7}{|c|}{ Sexual partners in 6 months before Ibiza }} \\
\hline (ref) None & 1 & & & & & \\
\hline 1 & 1.88 & (1.23 to 2.89$)$ & 2.00 & (0.91 to 4.41$)$ & 3.25 & (1.34 to 7.89 ) \\
\hline $2-5$ & 3.76 & ( 2.43 to 5.82 ) & 2.17 & (0.98 to 4.81 ) & 4.31 & (1.81 to 10.24 ) \\
\hline 6 or more & 14.96 & (7.45 to 30.05 ) & 4.39 & (1.80 to 10.72$)$ & 25.78 & (8.88 to 74.89 ) \\
\hline \multicolumn{7}{|c|}{$\begin{array}{l}\text { *Had unprotected sex identifies individuals that did not use a condom every time they had sex in lbiza. } \\
\text { Reference categories for each variable are identified with (ref). Statistics utilise a stepwise logistic regression } \\
\text { analysis with variables that are not significant }(p \geqslant 0.05 \text { ) being removed from the model and subsequently the } \\
\text { model recalculated. Such factors are identified with "NS." Analyses of having had unprotected sex and sex with } \\
\text { more than one partner in lbiza are both limited to individuals who had sex while abroad. }\end{array}$} \\
\hline
\end{tabular}


and by whether individuals had sex with non-UK residents. Of all males who had sex in Ibiza, 38 (15.8\%) had homosexual sex at least once while on the island. There was no significant difference in the proportion of males having unprotected sex in Ibiza between those who had homosexual sex (44.1\% had unprotected sex; 15/34) and those who had heterosexual sex only $(42.9 \%$ had unprotected sex; $\left.\chi^{2}=0.16, \mathrm{p}=0.89, \mathrm{n}=218\right)$.

Overall, $8.6 \%$ of respondents had sex with a non-UK resident. Among those who had sex in Ibiza, 20.3\% of men had sex with a non-UK resident compared with $3.8 \%$ of women $\left(\chi^{2}=19.01, \mathrm{p}<0.001, \mathrm{n}=369\right)$. For men, there was no significant difference in the proportion of individuals having unprotected sex in Ibiza between those that had sex with non-UK residents $(43.3 \%)$ and those that only had sex with UK residents (41.3\%; $\chi^{2}=0.06, \mathrm{p}=0.81, \mathrm{n}=217$ ). Analysis of unprotected sex among women having sex with non-UK residents was not undertaken owing to small sample size.

\section{DISCUSSION}

Despite significant UK policy developments in sexual health, ${ }^{21}{ }^{22}$ little attention has been paid to people's behaviour when outside the United Kingdom. However, over 17 million visits abroad are made by young people (aged 16-34) from the United Kingdom every year. ${ }^{23}$ Many now choose international nightlife resorts and the popularity of such resorts is increasing. ${ }^{18}$ Within the United Kingdom, and elsewhere, Ibiza continues to spearhead young people's passion for such holidays. However, public and professional impressions of behaviour on the island (and at other international dance resorts) are often based on highlights from selected individuals disseminated through television or other media formats. Here, using a sample of around 1500 individuals visiting the island we have begun to identify the actual risks to sexual health arising from increasing dance music tourism. Inevitably, our methodology relied on the accuracy of self reported data and the assumption that respondents are broadly representative of the population in question. Our anonymous design resulted in an average compliance of $90 \%$ among those who were approached and informed of the questionnaire's nature. However, this methodology also resulted in not all questions being completed by all individuals; although nearly all questions were answered by over $85 \%$ of respondents. Furthermore, as analyses of both sex with non-UK residents and homosexual sex were limited to 2002 data, for these groups sample sizes were relatively small. However, given the dearth of existing data on sex in international nightlife resorts, our analyses represent at least a preliminary exploration of sexual risk behaviour and nightlife tourism.

Although for most individuals the attraction of Ibiza was not specifically to have sex (table 1), the majority did have sex while on holiday (table 2). Not surprisingly those visiting with partners were significantly more likely to have sex in Ibiza. However, they were also significantly less likely to always use condoms (table 3 ). Frequently, those in long term relationships consider themselves less at risk from STIs. ${ }^{24}$ However, here we have shown that, of those who regard themselves as being in long term relationships, $9.4 \%$ had more than one sexual partner during the 6 months before visiting Ibiza and $6.2 \%$ had sex with at least one person (other than their partner) while in Ibiza (table 2). Both in the United Kingdom and abroad more work continues to be needed in order to make sexual health messages relevant to young people in relationships which may in reality be relatively transient or not exclusive.

Most individuals arrive in Ibiza without sexual partners (table 1) and just under half of these have sex while on the island with most always using a condom with every partner (table 2). However, those that do have sex in Ibiza (and arrive without a sexual partner) often accumulate more than one sexual partner during an average visit (table 2 ). In fact, on average such individuals accumulate as many new partners in an average 10 day stay as they do over an entire 6 months before their visit. Often based on this latter group, young people's image of Ibiza can be one of carefree sex and indulgence with little or no publicity being given to the majority who do not acquire new sexual partners or who use condoms consistently when they do (table 2). However, peer pressure can be an important influence on young people's behaviour ${ }^{25}$ and, consequently, new health promotion initiatives should acknowledge widespread condom use even in locations such as Ibiza.

Having sex, having unprotected sex, and having sex with more than one person abroad were all positively associated with having higher numbers of partners in the United Kingdom (table 3). Thus, those most likely to contract STIs abroad are also those most likely to have multiple sexual partners in the United Kingdom and therefore, potentially best placed to transmit STIs on their return. This relation between sex abroad and at home emphasises the importance of initiatives to promote safe sex on holidays and ensure that condoms and contraceptives are easily available throughout international resorts.

As with previous studies, ${ }^{26}{ }^{27}$ we identified significant associations between illicit drug use and sexual behaviour (in Ibiza) although there was no significant association between illicit drug use and unprotected sex (table 3). However, levels of smoking tobacco were high among this population (table 1) and were strongly linked both to having unprotected sex and to having more than one sexual partner in Ibiza (table 3). This is consistent with findings elsewhere in Europe, ${ }^{28}$ which also identified smoking as a better predictive factor for unsafe sex than recreational drug or alcohol use. Rather than a causative relation it is likely that links between unprotected sex, multiple sexual partners, and smoking reflect a predisposition to risk taking behaviour among certain individuals. ${ }^{29}$ Regardless of their relation, sexual risk and other risk behaviours, including drug use and smoking, are all at significantly higher levels in those populations visiting nightlife resorts. ${ }^{419}$ Consequently, health interventions in international dance resorts, or with individuals who visit them frequently, provide an opportunity to address many of the risks faced by young people in groups who experience them most often. However, tackling such risk behaviours requires the development of interventions sensitive to the evolving association between sexual behaviour, illicit substance use, and consumption of alcohol and tobacco.

Finally, having sex with a non-UK resident was associated with being male and over a fifth of all men (who had sex in Ibiza) had sex with a non-UK resident. Those having sex with non-UK residents were no more likely to have unprotected sex. Despite this, however, our results suggest that of every 1000 individuals (16-35 years) visiting the island around 85 will have sex with at least one non-UK resident and over a third of such individuals will have unprotected sex while in Ibiza. With over 250000 young people from the United Kingdom each year visiting just Ibiza, this represents a substantial conduit for transmission of STIs between countries.

As larger proportions of young people's time are spent outside the United Kingdom, strategies to protect sexual health must also adopt an international perspective. In England, primary care trusts (PCTs) now have explicit responsibility for the health of their local populations. ${ }^{30}$ Such health organisations should invest in protecting the 


\section{Key messages}

- While increasing numbers of young people travel abroad each year to sample international nightlife, very little information is available on their sexual behaviour

- Here we identify that most such individuals do not acquire new sexual partners while abroad and the majority who do always use condoms

- However, a significant minority acquire multiple sexual partners abroad and do not consistently practise safe sex. Such individuals are also those most likely to have multiple partners in the United Kingdom. Consequently, their behaviour is a significant risk factor in the national and international transmission of STls

- Action to protect the sexual health of millions of young people travelling abroad is urgently needed and requires investment from local health services, policy development at regional and national levels, and collaborative working with those in the travel and nightlife industries.

sexual health of their residents not only while at home but increasingly when holidaying abroad. However, delivering good sexual health interventions to millions of young people travelling abroad also requires collaboration with tour operators, airlines and airports, event organisers, health protection organisations, sexual health experts, and health services abroad. ${ }^{19}$ Consequently, action at regional and national levels should encourage such partnerships and ensure sexual health policy addresses the needs of young UK residents while abroad and the needs of young people from abroad holidaying in the United Kingdom. Without such measures to protect the health of young people abroad, already elevated rates of STIs and unwanted pregnancies in the United Kingdom may continue to climb, fuelled by the mixture of media hype, substance use and opportunity associated with dance music tourism.

\section{ACKNOWLEDGEMENTS}

Statistical support was provided by Dr Penny Cook and revisions of initial manuscripts benefited from comments by Jim McVeigh. Much of this work was undertaken as part of regional health monitoring for the North West Region and we are grateful for the continued support of the regional office and, in particular, Professor John Ashton and Professor Qutub Syed. We also thank anonymous referees for their constructive comments on an earlier version of this manuscript.

\section{CONTRIBUTORS}

MAB, conception and design, acquisition of funding, analysis and interpretation of data, drafting and revision of article; $\mathrm{KH}$, acquisition of data, drafting and revision of article; RT, conception and design, acquisition of funding, revision of article; $\mathrm{AB}$, conception and design, acquisition of funding, revision of article.

\section{Authors' affiliations}

M A Bellis, K Hughes, Centre for Public Health, Liverpool John Moores University, Liverpool L3 2AP, UK

R Thomson, South Sefton Primary Care Trust, Liverpool, UK

A Bennett, HIT, Liverpool, UK
Funding: This study was undertaken as part of regional monitoring for the North West Health Region.

Conflict of interest: none.

\section{REFERENCES}

1 Public Health Laboratory Service Communicable Disease Surveillance Centre. Sexual Health in Britain: recent changes in high risk sexual behaviours and the epidemiology of sexually transmitted infections including HIV. London: Public Health Laboratory Service, 2002.

2 Social Exclusion Unit. Teenage pregnancy. London: Stationery Office, 1999.

3 Wellings K, Macdowell W, Catchpole $M$, et al. Seasonal variations in sexual activity and their implications for sexual health promotion. $J R$ Soc Med 1999:92:60-4

4 Bellis MA, Hale G, Bennett A, et al. Ibiza uncovered: changes in substance use and sexual behaviour amongst young people visiting an international nightlife resort. Int J Drug Policy 2000;1 1:235-44.

5 Eiser JR, Ford N. Sexual relationships on holiday: a case of situational disinhibition? J Soc Pers Relat 1995; 12:323-39.

6 Parnell AM, Rodgers JL. Seasonality of induced abortion in North Carolina. J Biosoc Sci 1998;30:321-332.

7 Smeaton GL, Josiam BM, Dietrich UC. College students' binge drinking at a beach-front destination during spring break. J Am Coll Health 1998;46:247-54

8 Apostolopoulos Y, Sönmez S, Yu CH. HIV-risk behaviours of American spring break vacationers: a case of situational disinhibition? Int J STD AIDS 2002;13:733-43

9 Carter S, Horn K, Hart G, et al. The sexual behaviour of international travellers at two Glasgow GUM clinics. Int J STD AIDS 1997;8:336-8.

10 Clift SM, Forrest SP. Factors associated with gay men's sexual behaviours and risk on holiday. AIDS Care 1999;11:281-95.

11 Clark P, Cook PA, Syed Q, et al. Re-emerging syphilis in the north west: lessons from the Manchester outbreak. Liverpool: Public Health Sector, Liverpool John Moores University, 2001.

12 Fenton KA. Sexual health and HIV positive individuals: emerging lessons from the recent outbreaks of infectious syphilis in England. Commun Dis Public Health 2002;5:4-6.

13 Unlinked Anonymous Surveys Steering Group. Prevalence of HIV and hepatitis infections in the United Kingdom 2000: annual report of the Unlinked Anonymous Prevalence Monitoring Programme. London: Department of Health, 2001.

14 Cook PA, Towle A, Rimmer P, et al. HIV and AIDS in the north west of England 2001. Liverpool: Centre for Public Health, Liverpool John Moores University, 2002.

15 Department of Health. Getting ahead of the curve: a strategy for combating infectious diseases (including other aspects of health promotion). London: DoH, 2002.

16 Smith AMA, Rosenthal D. Sex, alcohol and drugs? Young people's experience of schoolies week. Aust N Z J Public Health 1997;21:175-80.

17 Centre d'Investigació i de Tecnologies Turístiques de les Illes Balears. Despeses turístiques 2001. Palma de Mallorca, Spain: Conselleria de Turisme, Gover de les Illes Balers, 2002.

18 Mintel International Group Limited. Youth holidays. London: Mintel International Group Limited, 2000.

19 Bellis MA, Hughes K, Lowey H. Healthy nightclubs and recreational substance use: from a harm minimisation to a healthy settings approach. Addict Behav 2002;27:1025-35.

20 SPSS Inc. SPSS Base 11.0. User Guide. USA: SPSS Inc. 2001.

21 Department of Health. Government response to the first annual report of the independent advisory group on teenage pregnancy. London: DoH, 2002.

22 Department of Health. The national strategy for sexual health and HIVimplementation action plan. London: DoH, 2002.

23 National Statistics. Travel trends: a report on the 2001 International Passenger Survey. London: Stationery Office, 2002.

24 Jadack RA, Fresia A, Rompalo AM, et al. Reasons for not using condoms of clients at urban sexually transmitted diseases clinics. Sex Transm Dis 1997;24:402-8.

25 Seidman E, Chesir-Teran D, Friedman JL, et al. The risk and protective functions of perceived family and peer microsystems among urban adolescents in poverty. Am J Community Psychol 1999;27:211-37.

26 Shrier LA, Emans SJ, Woods ER, et al. The association of sexual risk behaviors and problem drug behaviors in high school students. J Adolesc Health 1997;20:377-83.

27 Santelli JS, Robin L, Brener ND, et al. Timing of alcohol and other drug use and sexual risk behaviors among unmarried adolescents and young adults. Fam Plann Perspect 2001;33:200-5.

28 Calafat A, Juan M, Fernandez C, et al. Enjoying the night: the role of moderation. Valencia, Spain: IREFREA, 2003.

29 Cook PA, Bellis MA. Knowing the risk: relationships between risk behaviour and health knowledge. Public Health $2001 ; 115: 54-61$.

30 Department of Health. Shifting the balance of power in the NHS: securing delivery. London: DoH, 2001. 